
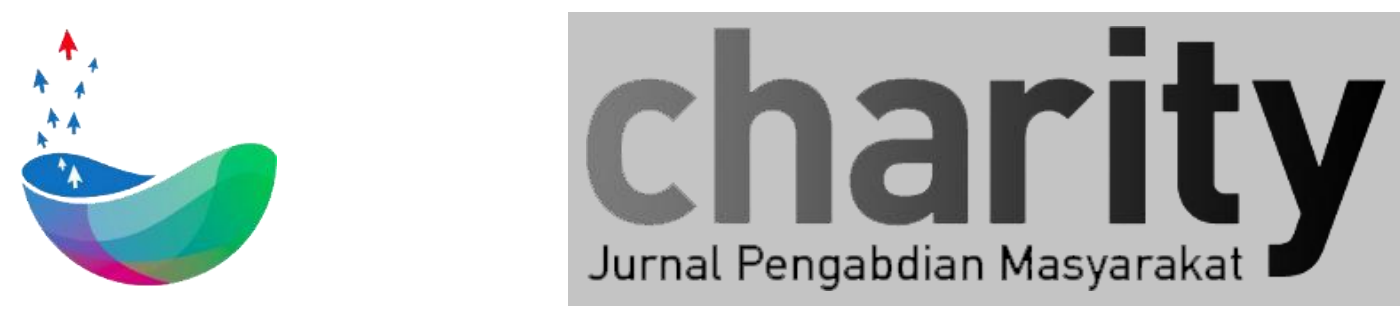

\title{
CLOUD CATALOG DAN PENGINTEGRASIAN MARKET PLACE DAN SOSIAL MEDIA UNTUK MEMBANTU PENJUALAN UMKM DI ERA NEW NORMAL
}

\author{
Retno Setyorini ${ }^{1}$, Bachruddin Saleh Luturlean ${ }^{2}$, Rohmat Saragih ${ }^{3}$, Agus Maolana Hidayat ${ }^{4}$, Pramitha Aulia ${ }^{5}$, Nuslih \\ Jamiat $^{6}$, Patrick Adolf Telnoni ${ }^{7}$, Rennyta Yusiana ${ }^{8}$, Arif Kuswanto ${ }^{9}$ \\ 1,2,3,4,5,6,9 Program Studi S1 Administrasi Bisnis, Fakultas Komunikasi dan Bisnis, Universitas Telkom \\ ${ }^{7}$ Program Studi D3 Sistem Informasi, Fakultas Ilmu Terapan, Universitas Telkom \\ ${ }^{8}$ Program Studi D3 Manajemen Pemasaran, Fakultas Ilmu Terapan, Universitas Telkom \\ * retnosrini@telkomuniversity.ac.id, bachruddinsaleh@telkomuniversity.ac.id, saragih@telkomuniversity.ac.id, agusmh@telkomuniversity.ac.id, \\ mithpsy@telkomuniversity.ac.id,nuslihjamiat@telkomuniversity.ac.id, patrickadolf@telkomuniversity.ac.id, \\ rennytayusiana@telkomuniversity.ac.id, arifkuswanto@telkomuniversity.ac.id
}

\section{INFO ARTIKEL}

Diterima 11 Januari 2021

Direvisi 11 November 2021

Disetujui 06 Desember 2021

Tersedia Online 04 Februari 2022

Keyword: Cloud Catalog, Media Sosial, Marketplace, UMKM

\begin{abstract}
ABSTRAK
Paguyuban Pengusaha Kecil dan Menengah (PPKM) Kab. Bandung, yang saat ini beranggotakan 300 jenis usaha, memiliki tujuan membangun kemandirian pengusaha kecil dan menengah yang professional, kuat serta bermanfaat bagi bangsa dan Negara. Hal ini tentunya memerlukan suatu sistem yang mendukung operasional dalam memasarkan produk mereka. Cloud Catalog bertujuan untuk menghimpun data yang berkaitan dengan produk UMKM dan penjualan di masa Era New Normal. Dengan semakin berkembangnya teknologi, maka hal ini dapat membantu UMKM dalam memperluas jangkauan pasar dalam memasarkan produknya. Namun dari seluruh anggota Paguyuban Usaha Kecil Menengah Regional Kabupaten Bandung (PPKM), masih dibawah $15 \%$ anggota usaha yang telah memiliki website dan menggunakan media sosial untuk mempromosikan produknya. Sebagian besar anggota masih menggunakan media konvensional seperti brosur dan pameran dalam mempromosikan produknya. Pembangunan Cloud Catalog dengan mengintegrasikan marketplace dan social media yang digunakan anggota PPKM dalam memasarkan produknya, diharapkan mampu membantu mengelola penjualan produk secara terpadu sehingga dapat meningkatkan penjualan produk UMKM. Pembangunan Cloud Catalog tersebut dilaksanakan melalui Kegiatan Pengabdian kepada Masyarakat yang dilaksanakan oleh dosen dan mahasiswa Fakultas Ilmu Terapan (FIT) dan Fakultas Komunikasi dan Bisnis (FKB).
\end{abstract}

Korespondensi:

Direktorat Penelitian dan Pengabdian Masyarakat, Universitas Telkom

Jl. Telekomunikasi No. 1, Terusan Buah Batu, Bandung, 40257

Indonesia

E-mail: charity@ telkomuniversity.ac.id

ORCID ID:

Penulis Pertama: Retno Setyorini https://doi.org/xxx 
Paper_reg_number xxx @ The Authors. Published by Directorate of Research and Community Service, Telkom University.

This is an open access article under the xxx license (https://creativecommons.org/licenses/xxx)

\section{Pendahuluan}

Usaha mikro, kecil dan menengah (UMKM) mempunyai peran penting dalam membangun dan mengembangkan perekonomian nasional. Usaha mikro, kecil dan menengah (UMKM) juga menjadi motor penggerak proses pemulihan penurunan perekonomian, terlebih dalam masa kritis akibat pandemi covid-19 saat ini. Bahkan UMKM menjadi tulang punggung penyediaan lapangan kerja karena secara konsisten menyerap sekitar 97\% tenaga kerja Indonesia [1].

Sejalan dengan tingginya penyerapan tenaga kerja, kontribusi UMKM terhadap produk domestik bruto (PDB) juga relatif tinggi. UMKM menyumbang 60,34\% PDB Indonesia berdasarkan sensus ekonomi 2016 di mana sektor UMKM menyumbang 58,18\% terhadap total investasi dan $14,17 \%$ terhadap total ekspor [1].

Paguyuban Pengusaha Kecil Menengah Regional Kabupaten Bandung (PPKM) merupakan wadah untuk mensinergikan berbagai kegiatan yang akan meningkatkan kesejahteraan para pelaku usaha yang termasuk golongan kecil dan menengah di wilayah Kabupaten Bandung, yang didirikan pada tanggal 25 Januari 2017. PPKM terpusat di Gedung Moh. Toha Soreang Kabupaten Bandung. Hadirnya paguyuban ini, diharapkan dapat menjadi pilar untuk menyokong perekonomian masyarakat, serta berperan sebagai wahana manifestasi inovasi, kreatifitas, dan inovasi pelaku usaha.

PPKM memiliki peran yang sangat strategis, karena dapat menggerakkan anggotanya untuk "tubuh dan besar bersama" dengan menggerakkan kegiatan ekonomi masyarakat dan sekaligus menjadi tumpuan sumber pendapatan dari sebagian masyarakat dalam meningkatkan kesejahteraan.

Dalam 25 tahun terakhir, kontribusi UMKM kepada PDB stagnan pada kisaran $60 \%$. Stagnasi kontribusi pertumbuhan kontribusi sektor UMKM terhadap PDB, terkait dengan daya saing. Menurut Pusat Perdagangan Dunia (ITC), ada tiga pilar yang menjadi parameter daya saing usaha di level mikro, yakni kapasitas untuk bersaing (compete), kapasitas untuk terhubung (connect), dan kapasitas untuk berubah (change). Kapasitas untuk bersaing terkait dengan operasi perusahaan dan efisiensi terkait biaya, waktu, kualitas, dan kuantitas. Adapun kapasitas untuk terhubung berkaitan dengan kemampuan untuk mengumpulkan dan memanfaatkan informasi serta pengetahuan bisnis yang relevan. Sementara kapasitas untuk berubah terkait dengan kemampuan perusahaan untuk mengeksekusi perubahan sebagai respons atau antisipasi atas dinamika pasar [1].

Kondisi pandemi saat ini membuat semua UMKM berusaha untuk kembali bangkit dan dapat menghasilkan pemasukan. Begitu juga UMKM anggota PPKM mengalami kondisi yang sama. Dalam kondisi yang kita kenal dengan New Normal, dimana semua pelaku usaha kembali beraktivitas dengan protokol keamanan COVID-19. Tentunya dampak ekonomi yang disebabkan oleh pandemi ini membuat pelaku 
UMKM harus lebih pandai untuk memasarkan produknya. Maka kegiatan pengabdian masyarakat ini membantu anggota PPKM agar dapat mengembangkan aplikasi Catalog milik PPKM yang akan diintegrasikan dengan marketplace dan berbasis cloud application. Cloud Application memiliki fleksibilitas yang baik dan biayanya murah, sehingga sangat cocok dengan kondisi ekonomi UMKM.

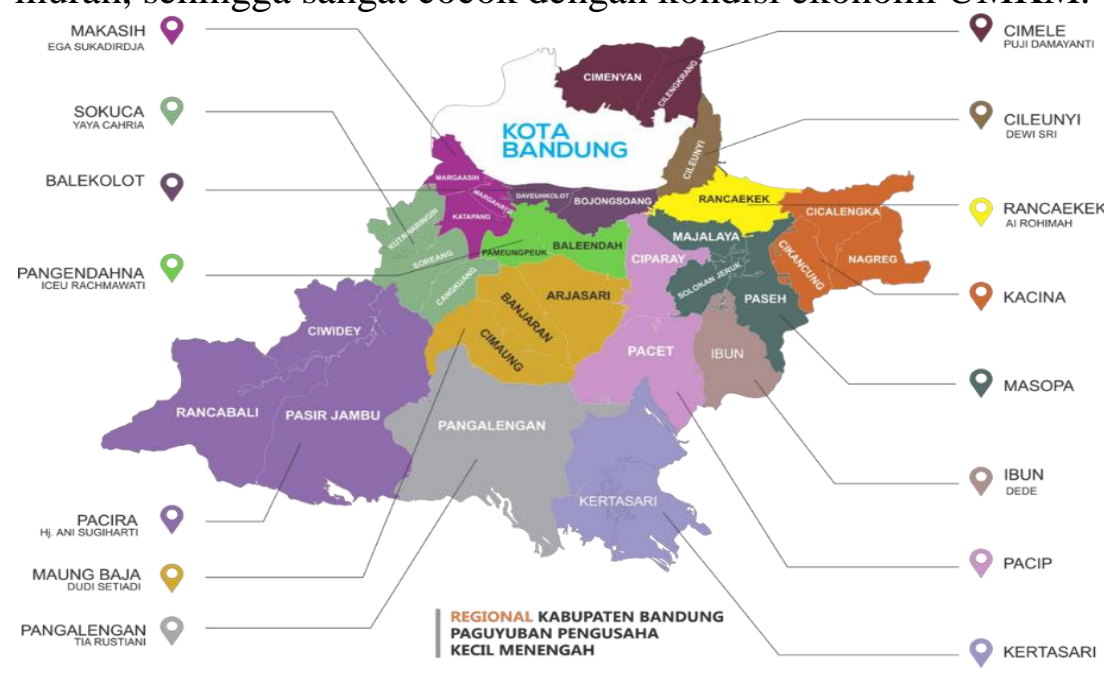

Gambar 1 Wilayah Kerja dan kantor Perwakilan PPKM

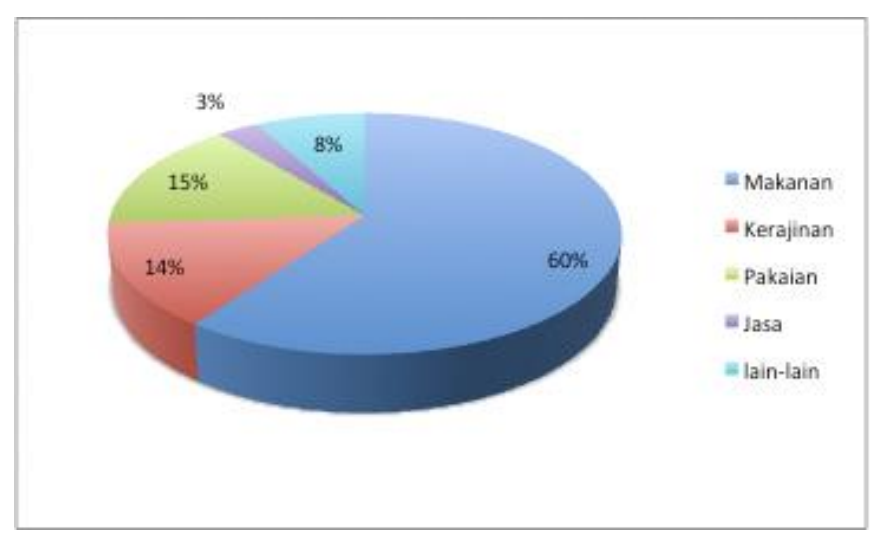

Gambar 2 Jenis Usaha PPKM

Gambar 2, merupakan informasi jenis usaha anggota dari PPKM. Usaha yang dijalankan PPKM didominasi oleh usaha makanan (kemasan ataupun non kemasan), kerajinan tangan, pakaian, jasa dan lain sebagainya.

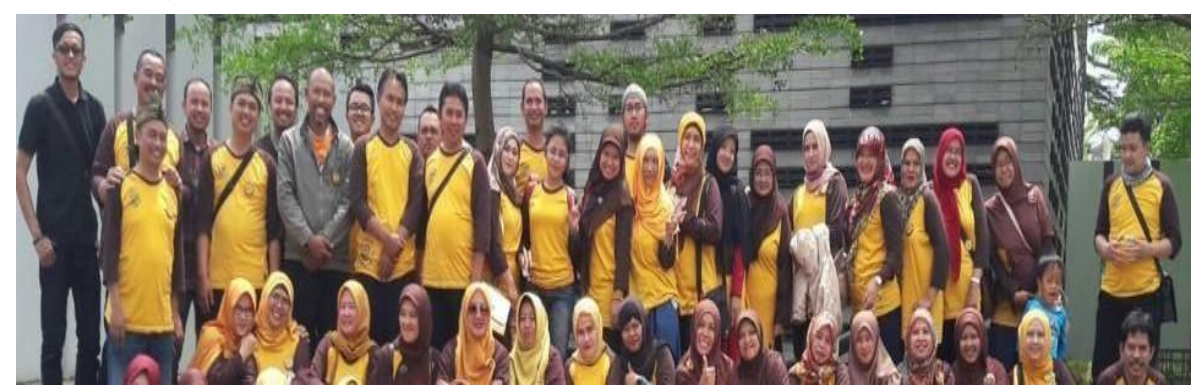

Gambar 3 Sebagian Anggota PPKM 


\section{Tujuan Kegiatan}

Kegiatan pengabdian masyarakat ini dilaksanakan dengan tujuan sebagai berikut:

1. Perancangan dan pembuatan Cloud Catalog Produk UMKM dibawah Komunitas PPKM Kabupaten Bandung

2. Sosialisasi Katalog Produk UMKM dengan integrasi Marketplace untuk mendongkrak penjualan produk UMKM

3. Pelatihan Media sosial dan digital marketing untuk UMKM dibawah Komunitas PPKM Kabupaten Bandung pada kondisi new normal

Adapun target luaran dari kegiatan pengabdian masyarakat ini adalah berupa:

1. Pengembangan Katalog UMKM dengan Intergrasi Marketplace

2. Sosialisasi Katalog UMKM dengan Intergrasi Marketplace

3. Pelatihan Sosial Media dan Digital Marketing pada kondisi New Normal

\section{Metode Pelaksanaan Kegiatan}

Kegiatan pengabdian masyarakat ini dilaksanakan pada tanggal 6 Januari 2020 secara online melalui kegiatan webinar. Detail kegiatan utama dapat dilihat pada Tabel 1 Adapun dukungan masyarakat terhadap tiap kegiatan dapat dilihat pada Tabel 2.

Tabel 1 Detail Metode Pelaksanaan Kegiatan

\begin{tabular}{|c|l|l|}
\hline No & \multicolumn{1}{|c|}{ Kegiatan } & \multicolumn{1}{|c|}{ Metode Pelaksanaan } \\
\hline 1 & $\begin{array}{l}\text { Pengembangan Cloud Katalog } \\
\text { UMKM dengan Intergrasi } \\
\text { Marketplace }\end{array}$ & $\begin{array}{l}\text { Melakukan Analisa kebutuhan UMKM } \\
\text { dan pengembangan Katalog UMKM } \\
\text { yang diintegrasikan dengan } \\
\text { marketplace. }\end{array}$ \\
\hline 2 & $\begin{array}{l}\text { Sosialisasi Cloud Katalog } \\
\text { UMKM dengan Intergrasi } \\
\text { Marketplace }\end{array}$ & $\begin{array}{l}\text { Pendampingan dan Implementasi } \\
\text { katalog umkm yang sudah } \\
\text { diintegrasikan dengan marketplace. }\end{array}$ \\
\hline 3 & $\begin{array}{l}\text { Pelatihan Sosial Media dan } \\
\text { Digital Marketing pada kondisi } \\
\text { New Normal }\end{array}$ & $\begin{array}{l}\text { Pendampingan kepada mitra secara } \\
\text { online / onsite mengenai digital } \\
\text { marketing dan peranan sosial media di } \\
\text { kondisi new normal. }\end{array}$ \\
\hline
\end{tabular}

Tabel 2 Bentuk Partisipasi Masyarakat

\begin{tabular}{|l|l|l|}
\hline No & Kegiatan & Partisipasi Masyarakat \\
\hline 1 & $\begin{array}{l}\text { Pengembangan Cloud Katalog } \\
\text { UMKM dengan Intergrasi } \\
\text { Marketplace }\end{array}$ & $\begin{array}{l}\text { Membantu tim perancang dalam } \\
\text { mengidentifikasi kebutuhan dan } \\
\text { memberikan contoh produk untuk } \\
\text { katalog. }\end{array}$ \\
\hline 2 & $\begin{array}{l}\text { Sosialisasi Cloud Katalog UMKM } \\
\text { dengan Intergrasi Marketplace }\end{array}$ & $\begin{array}{l}\text { Sebagai peserta kegiatan } \\
\text { Melatihan Sosial Media dan Digital } \\
\text { Marketing pada kondisi New }\end{array}$ \\
\hline
\end{tabular}




\section{Gambaran Transfer IPTEKS}

IPTEK yang diberikan kepada PPKM selaku mitra pada kegiatan pengabdian masyarakat ini berupa cloud catalog, yang terdiri dari (1) Cloud catalog untuk membantu pemasaran produk PPKM, (2) Pendampingan dan sosialisasi penggunaan cloud catalog, dan (3) Pendampingan sosialisasi dan edukasi pentingnya menggunakan media sosial dan digital marketing dalam memasarkan produk-produk UMKM. Adapun gambarannya dapat dilihat pada gambar berikut ini:

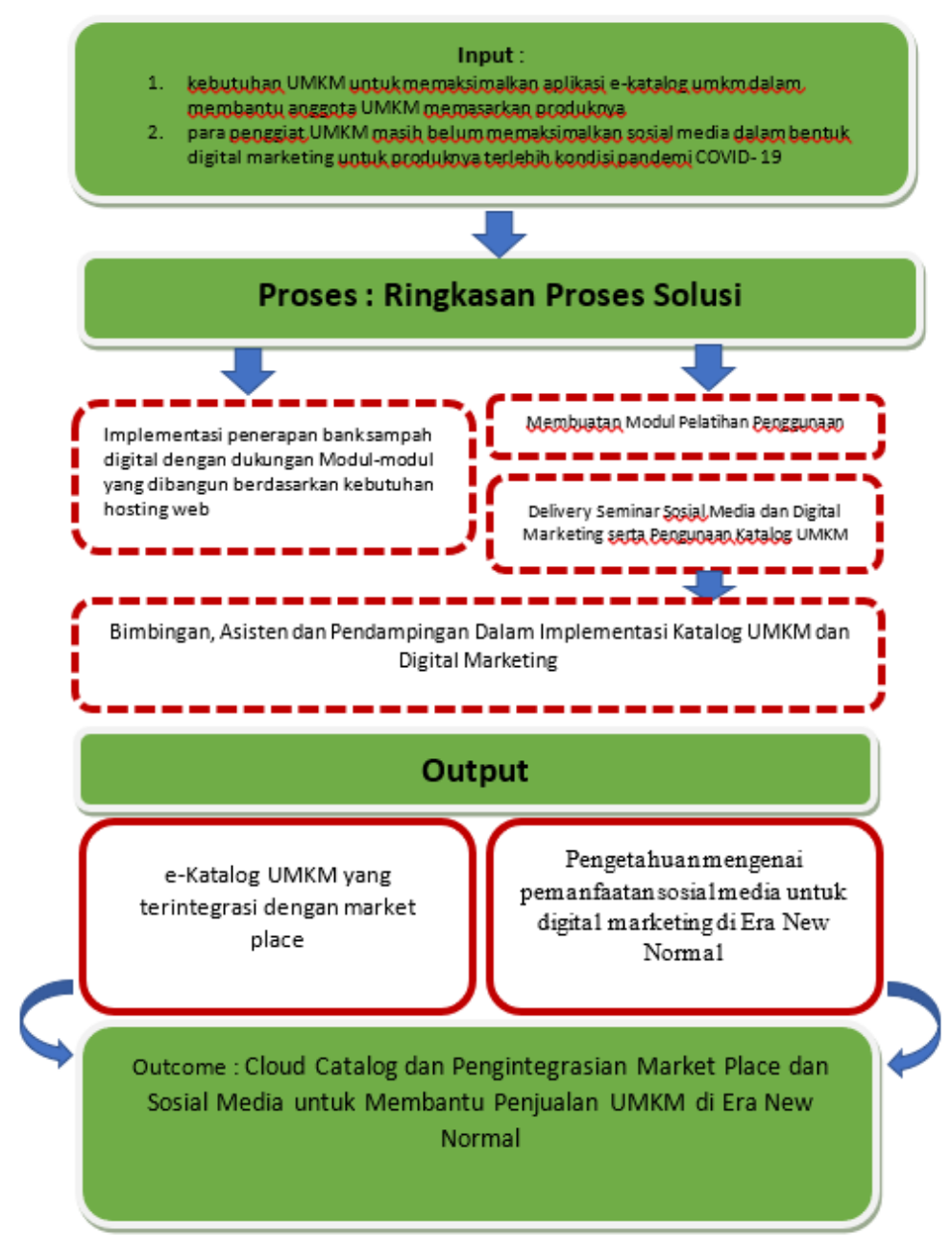

Evaluation : Evaluasi Pelaksanaan PKM

Gambar 4. Gambaran IPTEKS

\section{Hasil Kegiatan}

Pelaksanaan pengabdian kepada masyarakat ini melibatkan Paguyuban Pengusaha Kecil dan Menengah (PPKM) yang merupakan wadah pelaku usaha yang termasuk golongan kecil dan menengah di wilayah Kabupaten Bandung. Permasalahan mitra saat ini; 1) Hampir semua anggota PPKM belum dapat memanfaatkan 
marketplace dan media sosial secara efektif dan tepat guna untuk melakukan pemasaran, dan 2) Anggota PPKM belum memiliki catalog produk untuk pemasaran melalui marketplace dan media sosial untuk memudahkan pemasaran di era pandemi ini.

Berdasarkan permasalahan mitra tersebut, maka kegiatan pengabdian kepada masyarakat yang dilaksanakan, yaitu 1) Melakukan pengembangan cloud catalog UMKM dengan integrasi marketplace; 2) Memberikan sosialisasi penggunaan cloud catalog UMKM dengan integrasi marketplace; dan 3) Memberikan pelatihan mengenai penggunaan dan pentingnya sosial media serta digital marketing khususnya pada kondisi new normal.

Cloud computing mungkin masih samar terdengar bagi orang awam. Tetapi keberadaan cloud computing di era digital kini sebenarnya telah terasa di tengah masyarakat dalam kehidupan sehari hari seperti penggunaan email dan juga media sosial [2].

Cloud atau komputasi awan adalah sistem komputasi yang bekerja dengan menggunakan teknologi internet dan penyimpanan virtual. Istilah cloud(awan) merujuk pada storage yang terdiri dari sekumpulan server yang tersimpan rapi dan dikelola oleh penyedia layanan cloud [3].

Sistem cloud computing memungkinkan proses komputerisasi, menjalankan aplikasi, serta menyimpan dan mengolah data secara virtual dengan jaringan internet yang terhubung pada server. Semua data dan informasi yang dimiliki akan tersimpan dalam satu server, serta dapat diakses kapanpun dan dimanapun asalkan terkoneksi dengan jaringan internet [4].

Cloud computing mengutamakan kenyamanan dan kemudahan bagi para penggunanya. Hal lain yang terpenting adalah, pengguna juga tidak perlu menyiapkan storage berupa harddisk eksternal dengan kapasitas besar untuk media penyimpanan data-data, karena semua data telah tersimpan dalam storage cloud yang dapat di adjust kapasitasnya sesuai kebutuhan. Sistem storage cloud juga beroperasi secara online, sehingga lebih mudah dalam pengambilan data-datanya [4].

Pembuatan cloud catalog produk UMKM ini, dinilai efektif dan tepat guna dalam melakukan pemasaran dan penjualan produk bagi anggota PPKM. Karena, semua data tersimpan di server secara terpusat, data aman, kemudahan data akses dengan skalabilitas yang tinggi dan menghemat biaya dalam pembelian inventaris seperti infrastruktur, hardisk dan lainnya [2].

Selanjutnya, dilakukan sosialisasi cloud catalog produk UMKM dengan integrasi marketplace. E-Catalog ini akan sangat membantu anggota PPKM dalam memasarkan produknya di era new normal ini dan juga memudahkan konsumen dalam mencari produk yang dibutuhkannya.

Kegiatan ini juga memberikan pelatihan mengenai pentingnya sosial media dan digital marketing dalam keadaan new normal. Adanya bantuan dari penggunaan internet dan media website untuk penjualan 
produk dan melayani customer agar kinerja menjadi lebih efektif dan efisien dimana customer tidak perlu datang ke tempat [5].

Pada kegiatan pengabdian masyarakat Cloud Catalog ini PPKM diberikan bantuan berupa peralatan perangkat komputer multimedia yang diharapkan dapat membantu paguyuban UMKM untuk memfasilitasi anggotanya dalam teknologi informasi dan konten kreatif. Serta diberikan website PPKM.info untuk digunakan sebagai official website umkm untuk catalog dan marketplace yang sudah terintergrasi dengan media sosial.

Rangkaian acara yang dilakukan selama kegiatan ini mulai dari edukasi mengenai marketing dan konsumen, sosialisasi aplikasi di acara Webinar Pengabdian kepada Masyarakat pada tanggal 6 Januari 2021. Selanjutnya kegiatan ini akan berkelanjutan dan berkerjasama dengan Startup Mahasiswa - Smespedia, untuk keberlanjutan kegiatan baik di edukasi UMKM, pengelolaan Teknologi Informasi dan dukungan marketing digital.

Pasca kegiatan berlangsung, masyarakat diminta mengisi kuesioner sebagai feedback kepada penyelenggara. Hasil kuesioner menunjukkan bahwa masyarakat menilai bahwa kegiatan ini sesuai dengan tujuan dan kebutuhan masyarakat (25\% menyatakan setuju dan $75 \%$ menyatakan sangat setuju). Masyarakat juga mengharapkan program pengabdian masyarakat ini bisa lanjut dimasa yang akan datang. Adapun ringkasan hasil kuesioner dapat dilihat pada tabel berikut:

Tabel 3 Hasil Kuesioner Kepuasan Masyarakat

\begin{tabular}{|c|l|c|c|c|c|}
\hline No & \multicolumn{1}{|c|}{ Penilaian Terhadap Kegiatan } & $\begin{array}{c}\text { Sangat } \\
\text { Setuju }\end{array}$ & Setuju & $\begin{array}{c}\text { Tidak } \\
\text { Setuju }\end{array}$ & $\begin{array}{c}\text { Sangat } \\
\text { Tidak } \\
\text { Setuju }\end{array}$ \\
\hline 1 & $\begin{array}{l}\text { Program Pengabdian kepada Masyarakat ini } \\
\text { sudah sesuai dengan tujuan kegiatan itu sendiri. }\end{array}$ & 9 & 0 & 0 & 0 \\
\hline 2 & $\begin{array}{l}\text { Program Pengabdian kepada Masyarakat ini } \\
\text { sudah sesuai dengan kebutuhan masyarakat } \\
\text { sasarnya. }\end{array}$ & 9 & 0 & 0 & 0 \\
\hline 3 & $\begin{array}{l}\text { Waktu pelaksanaan program pengabdian } \\
\text { masyarakat ini relatif telah mencukupi sesuai } \\
\text { kebutuhan. }\end{array}$ & 5 & 4 & 0 & 0 \\
\hline 4 & $\begin{array}{l}\text { Dosen dan mahasiswa Universitas Telkom } \\
\text { bersikap ramah, cepat dan tanggap membantu } \\
\text { selama kegiatan. }\end{array}$ & 9 & 0 & 0 & 0 \\
\hline 5 & $\begin{array}{l}\text { Masyarakat setempat menerima dan } \\
\text { mengharapkan program pengabdian kepada } \\
\text { masyarakat Universitas Telkom saat ini dan masa } \\
\text { yang akandatang. }\end{array}$ & 9 & 0 & 0 & 0 \\
\hline \\
JUMLAH "SANGAT SETUJU" + "SETUJU"
\end{tabular}

\section{Kesimpulan}

Dari kegiatan pengabdian masyarakat "Cloud Catalog dan Pengintegrasian Marketplace dan Sosial Media untuk membantu Penjualan UMKM di Era New Normal" dapat disimpulkan:

1. Cloud catalog produk UMKM dengan integrasi marketplace sebagai sarana pemasaran dan penjualan, telah berhasil dibuat dan 
masyarakat sudah mendapatkan pelatihan penggunaannya secara online.

2. Pendampingan dan edukasi pemanfaatan sosial media dan digital marketing pada kondisi new normal sudah berhasil dilaksanakan kepada masyarakat secara online.

3. Masyarakat menilai bahwa kegiatan ini sesuai dengan tujuan serta kebutuhan masyarakat, dimana $25 \%$ menyatakan setuju dan $75 \%$ menyatakan sangat setuju.

\section{DAFTAR PUSTAKA}

[1] UMKM Menjadi Solusi Persoalan Ketenagakerjaan dan Permintaan. Koran Sindo. (2020, Agustus 5). https://nasional.sindonews.com/

[2] Pengertian, Manfaat, Cara Kerja dan Contoh Cloud Computing. (2015, 12 Oktober). https://lawavedesign.com/

[3] Rommalla, Syiti. 4 KelebihanAplikasi Berbasis Cloud yang Perlu Anda Tahu. (2019, 30 April). www.gadjian.com

[4] Apa Itu Cloud Computing? Cloudraya. (2020, 8 April). https://cloudraya.com/

[5] Shabur, Miftah Maulana, dkk. (2015). Implementasi E-Commerce Sebagai Media Penjualan Online (Sudi Kasus Pada Toko Pastbrik Kota Malang). Jurnal Administrasi Bisnis. Vol. 29 No. 1 Desember 2015. 